\title{
Intention to Seek Counseling Among Indonesian Students: Examining the Impact of Social Anxiety and Loneliness
}

\author{
Aprezo Pardodi Maba ${ }^{1}$, Andika Ari Saputra \\ Institut Agama Islam Ma'arif NU (IAIMNU) Metro Lampung, Indonesia \\ Qaprezopm@gmail.com ${ }^{1}$
}

\begin{abstract}
Article Information:
Received March 19, 2019

Revised April 3, 2019

Accepted April 3, 2019
\end{abstract}

Keywords: social anxiety; loneliness; intention to seek counseling; students

\begin{abstract}
This study was investigating the impact of social anxiety and loneliness toward intention to seek counseling, and loneliness as mediator in the relation of social anxiety towards intention to seek counseling. The participants were selected with cluster random sampling technique. Five hundred and two students from several regions in Indonesia were involved after confirm the participant consent and complete the online instruments of brief scale of loneliness for adolescents $(\alpha=0.709)$, social anxiety ( $\alpha=$ $0.780)$, and intention to seek counseling $(\alpha=0.746)$. The analysis data technique was used path analysis with mediation variable. The results of this study showed that, separately social anxiety and loneliness affected the intention to seek counseling, social anxiety affected loneliness, social anxiety with loneliness affected the intention to seek counseling, and the direct effect of social anxiety toward intention to seek counseling is higher than through loneliness as mediator variable.
\end{abstract}

\section{INTRODUCTION}

Many students experiencing psychological problem but felt hesitant to seek help from professional mental health care (Abdollahi, Hosseinian, Beh-Pajooh, \& Carlbring, 2017). Person who experiences psychological health problems ideally received access to getting assistance from professional staff or with fully aware themselves seeking and seeing the counselors, psychologists or people who are competent on the field of psychological health. However, many people who experience mental health disorders choose not to seek help (Corrigan, 2004), even someone with anxiety and lack of social interaction tends to have low social support and is not satisfied despite receiving assistance from others (Priel \& Shamai, 1995).

In educational context, particularly within school environment, many factors that trigger anxiety among students. The high target of learning achievement, competitive climate, solid provision of tasks, and rigorous assessment system are factors that cause anxiety (Arizona, Nurlela, \& Jannati, 2019). Several previous studies have found a positive relationship between social anxiety and loneliness. The findings of some of these studies focus on the relationship of social anxiety with loneliness and several other variables such as the relationship between social anxiety and loneliness in people with internet use disorders (Huan, Ang, \& Chye, 2014), making loneliness a partial mediator that causes a person to feel anxiety when socializing with others (Fontaine et al., 2009), the relationship of social anxiety with loneliness is caused by the existence of bad intentions that are afraid of being known by others (Huan et al., 2014), and the onset of social anxiety is a result of social expectations are 
not in accordance with reality (Cuming \& Rapee, 2010; Dykstra \& Fokkema, 2007; Peplau, 1982).

In other hand, the intention to seek counseling was depended on individual perceptions whether counseling helpful or not. Therefore, the credibility and relevance of counseling services provided determines whether someone will come to see the counselor or not when getting psychological problems (Kung, 2004). Asians are still worried about the stigma given by others when seeking psychological help (Kung, 2004). One aspect of stigma is withdrawing from social relationships because they feel anxious of the possibility of rejection from others (Jorm \& Griffiths, 2008; Vogel, Wade, \& Hackler, 2007). The more someone is avoided by the people around him, the less his intention to seek help from informal sources and has negative perceptions about these sources (Yap, Wright, \& Jorm, 2011). Loneliness is one indicator of psychological problems in adolescents who needed counseling (Solberg, Ritsma, Davis, Tata, \& Jolly, 1994). Other research finding have explained loneliness from a gender perspective, the finding state that lonely men are less likely to seek psychological help than women (Borys \& Perlman, 1985).This means that the relationship of social anxiety with the desire for counseling has been found (Jorm \& Griffiths, 2008; Kung, 2004; Vogel \& Wei, 2005). Anxiety about attachment to others has a significant relationship to the desire for counseling (Vogel \& Wei, 2005).

Although the results of previous studies mentioned above have shown links between social anxiety, loneliness and intention to seek counseling, however, none of these studies provide a clear picture of how loneliness can affect one's intention to seek counseling from professionals. The author will also determine the effect of social anxiety and loneliness as well as the intention to seek counseling. Then, the indirect effect of loneliness in the relationship social anxiety towards intention to seek counseling. In addition, author need to reaffirm the impact of social anxiety toward loneliness and social anxiety toward intention to seek counseling.

Based on the backgrounds, five research objectives were compiled, the impact of: 1) social anxiety intention to seek counseling, 2) loneliness toward intention to seek counseling, 3) social anxiety toward loneliness and, 4) social anxiety and loneliness toward intention to seek counseling, and 5) loneliness as mediator in the relation of social anxiety toward intention to seek counseling.

\section{METHODS}

Five hundred and two students volunteered to be involved in this study. Participants were junior high school students and came from several regions in Indonesia; South Sumatera, Banten, DKI Jakarta, Central Java and East Java.

The participants were selected with cluster random sampling technique. The author was used a network of students and alumni of guidance and counseling students who have worked in schools as teachers. The author asked them to provide confirmation of willingness to be an extension of the author's hand in collecting data. After agreement, the author sent link an online research instrument to teachers and student networks. They asked students in each school to filled out the instrument and be monitored directly. There are several participants filled the instrument more than once. To avoid data bias, the author had eliminated the multiple responses given by participants.

Three psychological scales were used guided by adaptation tests to various languages and cultures (Hambleton, Merenda, \& Spielberger, 2004). At first the scale was an English language then translated into Indonesian, then back translation to confirm the accuracy of language switching, lastly, it was tested again on its validity and reliability.

The psychological scale used to find out the participant loneliness is the brief scale of loneliness for adolescents (Roberts, Lewinsohn, \& Seeley, 1993). This scale has 8 items with 
each of 4 items of unfavorable item ("I feel fit with those around me") and 4 favorable items ("I feel alienated from others"). The higher the participants' score, the higher loneliness will be. Loneliness scale reliability score on this research is at 0.709 .

To determine the tendency of social anxiety psychological scale of Kashdan and Steger was used (Kashdan \& Steger, 2006). This psychological scale consists of 7 items with 5 alternative answers, $1=$ none at all, $2=$ little, $3=$ moderate, $4=$ many and $5=$ very much. Examples of statements used are "I worry about what other people think about me" and "I worry about what I say or do is wrong" with Cronbach's alpha 0.780. The higher the participants' score, the higher the social anxiety they experience.

The intention to seek counseling is measured by giving 15 types of problems that are often faced, participants are asked to choose their possibility to meet the counselor when experiencing the problem (Cash, Begley, McCown, \& Weise, 1975). Problems in this psychological scale include anxiety, alcoholic beverages, feelings of shame, sexual dysfunction, depression, conflict with parents, talking anxiety, difficulty finding spouses, career choices, insomnia, drug dependence, low self-esteem, anxiety tests, difficult to find friends and learning problems. There are four alternative answers given, with a score $1=$ highly unlikely, $3=$ unlikely, $3=$ likely and 4 very likely. The reliability value at 0.746 . The conclusion used in this scale is the higher the score shown by the participants, the higher their intention to meet the counselor to conduct counseling.

The author used multiple linear regression analysis to see the relationship between social anxiety, loneliness, and the desire for counseling. Then used path analysis to see the indirect effect.

\section{RESULTS AND DISCUSSION}

The data were collected and tabulated then statistical data analysis can be done. The descriptive data analysis mean, standard deviation and mode can be seen in Table 1 .

\begin{tabular}{ccc}
\hline Variable $(\mathbf{N}=\mathbf{5 0 2})$ & Mean & Deviation Standard \\
\hline Social Anxiety & 20.95 & 6.303 \\
Loneliness & 12.24 & 3.115 \\
Intention to Seek Counseling & 31.77 & 8.361 \\
\hline
\end{tabular}

Table 1. Mean, standard deviation.

Based on Table 1. Author made categorization for each variable. Social anxiety $(M=20.95)$ and loneliness $(M=12.25)$ included in low category. Fortunately, intention to seek counseling $(\mathrm{M}=31.77)$ included in average category.

Social anxiety predicts intention to seek counseling $\left(\beta=0.287, \mathrm{r}^{2}=0.082, \rho=0.000\right)$. Loneliness significantly affects intention to seek counseling $\left(\beta=0.170, \mathrm{r}^{2}=0.028, \rho=0.000\right)$. Social anxiety significantly affects loneliness $\left(\beta=0.277, \mathrm{r}^{2}=0.076, \rho=0.000\right)$. Social anxiety and loneliness together predict intention to seek counseling $\left(\beta=0.302, \mathrm{r}^{2}=0.091, \rho=0.000\right)$. More can be seen in Table 2.

\begin{tabular}{ccccc}
\hline $\begin{array}{c}\text { Direction of } \\
\text { relationship }\end{array}$ & $\boldsymbol{\beta}$ & $\mathbf{r}^{\mathbf{2}}$ & $\mathbf{P}$ & SE \\
\hline $\mathrm{SA} \rightarrow \mathrm{ISC}$ & 0.287 & 0.082 & 0.000 & 0.057 \\
$\mathrm{LO} \rightarrow \mathrm{ISC}$ & 0.170 & 0.028 & 0.000 & 0.118 \\
$\mathrm{SA} \rightarrow \mathrm{LO}$ & 0.277 & 0.076 & 0.000 & 0.021 \\
$\mathrm{SA} \& \mathrm{LO} \rightarrow \mathrm{ISC}$ & 0.302 & 0.091 & 0.000 & 0.119 \\
\hline
\end{tabular}

$\mathrm{SA}=$ Social Anxiety, $\mathrm{LO}=$ Loneliness, ISC = Intention to Seek Counselling.

Table 2. Variables impact on Intention to Seek Counselling 
In a row, the partial relationship and the effect of social anxiety towards intention to seek counseling is the highest, followed by social anxiety towards loneliness, and loneliness towards intention to seek counseling is the lowest. Based on Figure 1, the social anxiety on intention to seek counseling direct effect is higher $\left(c^{2}=0.302\right)$ than indirect effect which mediated by loneliness $(\mathrm{ab}=0.027)$.

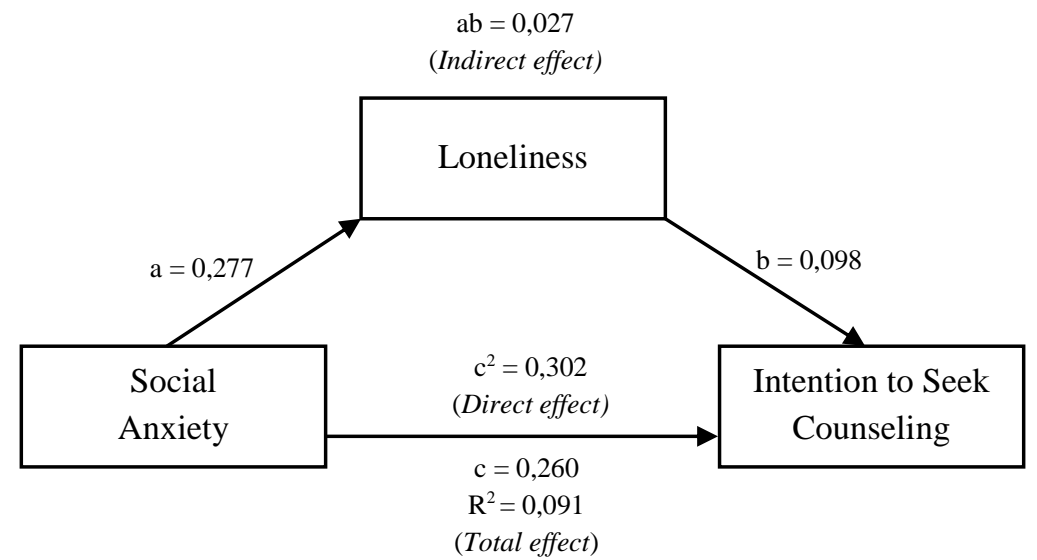

Figure 1 . The role of social anxiety on intention to seek counseling with loneliness as mediator

The finding in this study is social anxiety significantly affected intention to seek counseling. This finding related to some of the findings on previous studies. One aspect of stigma is withdrawing from social relationships because they feel anxious about the possibility of rejection from others (Jorm \& Griffiths, 2008; Vogel, Wade, \& Hackler, 2007). Asian people are still worried about the stigma given by others, especially when seeking psychological help (Kung, 2004). Group cohesiveness in the culture of Asians (including Indonesia) is in high category, so, "accepted" by the people around them is a necessity (Triandis, 1989).

People who experience anxiety about rejection by others tend to have the intention to seek counseling. Receive counseling is their way to identify experienced psychological problems so they get attention and connected with others (Vogel \& Wei, 2005). As well as the increasing awareness of the need to live life fully, more and more people are seeking help when experiencing anxiety (Ramaiah, 2003). One aspect of life fully is free from disturbing anxiety, awareness of the importance of living life fully makes the individual immediately identifying and find a way to relieve his/her anxiety so it will not affect the quality of life both physically and spiritually.

Men or women who experience social anxiety still consider the social rewards of their actions to express their experiences to others (Snell, 1989). In the context of counseling services, if the services provided by counselors are seen as providing social rewards for counselees who experiencing social anxiety can increase their motivation to meet counselors and receive counseling services to alleviate problems that they experiencing.

The loneliness significantly affects intention to seek counseling. Some previous studies also found similar things about the relationship between loneliness and the desire for counseling. Loneliness does not mean alone or do not have friends. Loneliness is a condition when a person experiences unpleasant feelings due to social relations that are built not in accordance with expectations (Peplau, 1982). Loneliness is characterized by reduced the quality and quantity of one's social relations (Newall et al., 2009).

Loneliness is one indicator of the psychological problems of adolescents who want counseling (Cash et al., 1975; Solberg, Ritsma, Davis, Tata, \& Jolly, 1994). In attribution theory (Weiner, 1985), in general, someone wants to find out what caused something 
happening in his life. Based on this premise, the author argues that people who experience loneliness have the desire to know why they experiencing those feelings. One way to get that information is to find a counselor to get counseling services.

In a study of differences in loneliness from a gender perspective, lonely men rarely sought psychological help than women (Addis \& Mahalik, 2003; Borys \& Perlman, 1985; Liddon, Kingerlee, \& Barry, 2018). Men feel loneliness higher than women (Borys \& Perlman, 1985). However, women are better at expressing their feelings than men. The main consideration for the actions of men not to seek help is the negative consequences that will be experienced when expressing their feelings (Borys \& Perlman, 1985). The negative consequences can be in the form of a helpless view of himself because he is unable to solve the problem independently (Pedersen, Vitaro, Barker, \& Borge, 2007).

However, there are also results of different studies which say that the more someone is shunned by the people around him the less desire to seek help and has negative perceptions about some sources of help (Yap, Wright, \& Jorm, 2011). It is a different finding, but need to be underlined that the source of help in question is informal sources such as family, friends and partners, not from formal sources such as counselors, psychologists or doctors who are professional service providers. People who experience loneliness tend to have different communication patterns, this is due to the low social skills they have. They prefer social media as a medium of communication in expressing personal and intimate matters (Bonetti, Campbell, \& Gilmore, 2010). It is only natural if the two research findings above say that people who experience loneliness do not seek help from their social environment. Even if there is an intention to get help, then the type of help that will be sought is online counseling. Online counseling uses social media or live radio interaction in building therapeutic relationships between counselees and counselors still needs to be tested for effectiveness (Mallen \& Vogel, 2005).

There is a relationship and a significant influence between anxiety and loneliness. This finding is in line with the findings of several previous studies which said there was a positive relationship between social anxiety and loneliness. The findings of some of these studies focus on the relationship of social anxiety with loneliness with several other variables such as the relationship between social anxiety and loneliness in people with internet use disorders (Huan et al., 2014), loneliness a partial mediator that causes a person to feel anxious while socializing with others (Fontaine et al., 2009), the relationship of social anxiety with loneliness caused by the existence of bad intentions that are feared to be known by others (Huan et al., 2014), often occurs in social relations with the opposite sex (Amil \& Bozgeyikli, 2015), and the onset of social anxiety is a result of social expectations that are not in accordance with reality (Cuming \& Rapee, 2010; Dykstra \& Fokkema, 2007; Peplau, 1982).

Social anxiety is an important predictor of loneliness (Amil \& Bozgeyikli, 2015; Bonetti et al., 2010; Pedersen et al., 2007). Findings in other studies in line with the findings of this study indicate that there is a positive relationship between social anxiety and loneliness. Using a sample of students, Amil and Bozgeyikil concluded that one of the reasons a person experiences loneliness is social anxiety (Amil \& Bozgeyikli, 2015). Social anxiety can cause communication problems such as difficulty in articulating thoughts and feelings to others. This inability becomes a trigger for rejection by the social environment and ends in the experience of feelings of loneliness (Pedersen et al., 2007).

The Social anxiety and loneliness together relate significantly and influence the intention to seek counseling. Author have presented various previous research findings that support the findings of this study. Social anxiety and loneliness are important variables in influencing a person to counseling (Amil \& Bozgeyikli, 2015; Bonetti et al., 2010; Cash et al., 1975; Pedersen et al., 2007; Ramaiah, 2003; Solberg et al., 1994; Vogel \& Wei, 2005). Lastly, 
the direct effect of social anxiety toward intention to seek counseling is higher than through loneliness as mediator variable.

Despite new findings in this study, the findings are only limited to investigating the relationship of social anxiety and loneliness with the intention to seek counseling. So, author hope that in future studies can involving other factors that have the possibility of influencing the intention to seek counseling, comparing anxiety, loneliness or the intention to seek counseling between men, women, children or adult or investigate the indirect effects of the variables used in this study.

The results of this study can be used by practitioners (counselors or guidance and counseling teachers) in conducting assessments or prognosis in order to provide appropriate services to the counselee. The findings in the study can be used as a basis for conducting further research on various variables that can affecting someone to counseling.

\section{CONCLUSIONS}

Based on the research findings, it can be concluded that social anxiety significantly influences the intention to seek counseling, a person's level of loneliness can predict the the intention to seek counseling, social anxiety affects loneliness and social anxiety and loneliness together become the important predictors that make a person want to seek counseling. The findings of this study can be used to optimize counseling services and become a reference in conducting further research.

\section{ACKNOWLEDGMENTS}

Acknowledgement are extended to all students who participated in the survey. Guidance and counseling teachers Astuti, Sepri Herzani, Mersiana, and Ardhaneswari for their contribution to promoting and recruiting to the survey. The author also extend gratitude to Dr. Subandi, M.M. who had given advice how to conduct this research and Wawan, M.Pd. for his help on statistical data analysis. Lastly, to Institut Agama Islam Ma'arif NU (IAIMNU) Metro Lampung for providing financial support for the conduct of the research.

\section{AUTHOR CONTRIBUTION STATEMENTS}

The authors had participated in the research and approved the final manuscript.

\section{REFERENCES}

Abdollahi, A., Hosseinian, S., Beh-Pajooh, A., \& Carlbring, P. (2017). Self-Concealment Mediates the Relationship Between Perfectionism and Attitudes Toward Seeking Psychological Help Among Adolescents. Psychological Reports, 120(6), 1019-1036. https://doi.org/10.1177/0033294117713495

Addis, M. E., \& Mahalik, J. R. (2003). Men, masculinity, and the contexts of help seeking. American Psychologist, 58(1), 5-14. https://doi.org/10.1037/0003-066X.58.1.5

Amil, O., \& Bozgeyikli, H. (2015). Investigating the Relationship between Social Appearance Anxiety and Loneliness of Turkish University Youth. Journal of Studies in Social Sciences, 11(1). Retrieved from http://infinitypress.info/index.php/jsss/article/view/1091

Arizona, A., Nurlela, N., \& Jannati, Z. (2019). Relaxation Technique within Group Counseling to Reduce Student's Anxiety on Facing Exam. Islamic Guidance and Counseling Journal, 2(1). 33-39. https://doi.org/10.25217/igcj.v2i1.310

Bonetti, L., Campbell, M. A., \& Gilmore, L. (2010). The relationship of loneliness and social anxiety with children's and adolescents' online communication. Cyberpsychology, 
Intention to Seek Counseling Among Indonesian Students: Examining the Impact of Social Anxiety and Loneliness

Behavior, and Social Networking, 13(3), 279-285. http://dx.doi.org/10.1089/cyber.2009.0215

Borys, S., \& Perlman, D. (1985). Gender Differences in Loneliness. Personality and Social Psychology Bulletin, 11(1), 63-74. https://doi.org/10.1177/0146167285111006

Cash, T. F., Begley, P. J., McCown, D. A., \& Weise, B. C. (1975). When counselors are heard but not seen: Initial impact of physical attractiveness. Journal of Counseling Psychology, 22(4), 273. https://doi.org/10.1037/h0076730

Corrigan, P. (2004). How stigma interferes with mental health care. American Psychologist, 59(7), 614. https://doi.org/10.1037/0003-066X.59.7.64

Cuming, S., \& Rapee, R. M. (2010). Social anxiety and self-protective communication style in close relationships. Behaviour Research and Therapy, 48(2), 87-96. https://doi.org/10.1016/j.brat.2009.09.010

Dykstra, P. A., \& Fokkema, T. (2007). Social and Emotional Loneliness Among Divorced and Married Men and Women: Comparing the Deficit and Cognitive Perspectives. Basic and Applied Social Psychology, 29(1), 1-12. https://doi.org/10.1080/01973530701330843

Fontaine, R. G., Yang, C., Burks, V. S., Dodge, K. A., Price, J. M., Pettit, G. S., \& Bates, J. E. (2009). Loneliness as a partial mediator of the relation between low social preference in childhood and anxious/depressed symptoms in adolescence. Development and Psychopathology, 21(2), 479-491. https://doi.org/10.1017/S0954579409000261

Hambleton, R. K., Merenda, P. F., \& Spielberger, C. D. (2004). Issues, designs, and technical guidelines for adapting tests into multiple languages and cultures. In Adapting educational and psychological tests for cross-cultural assessment (pp. 15-50). Psychology Press. https://doi.org/10.4324/9781410611758

Hofstede, G. (1984). Culture's consequences: International differences in work-related values (Vol. 5). Sage Publications. Retrieved from Google Scholar

Hofstede, G. (2001). Culture's consequences: Comparing values, behaviors, institutions and organizations across nations. Sage Publications. Retrieved from Google Scholar

Huan, V. S., Ang, R. P., \& Chye, S. (2014). Loneliness and Shyness in Adolescent Problematic Internet Users: The Role of Social Anxiety. Child \& Youth Care Forum, 43(5), 539-551. https://doi.org/10.1007/s10566-014-9252-3

Jorm, A. F., \& Griffiths, K. M. (2008). The public's stigmatizing attitudes towards people with mental disorders: how important are biomedical conceptualizations? Acta Psychiatrica Scandinavica, 118(4), 315-321. https://doi.org/10.1111/j.16000447.2008.01251.x

Kashdan, T. B., \& Steger, M. F. (2006). Expanding the topography of social anxiety: An experience-sampling assessment of positive emotions, positive events, and emotion suppression. Psychological Science, 17(2), 120-128. https://doi.org/10.1111/j.14679280.2006.01674.x

Kung, W. W. (2004). Cultural and practical barriers to seeking mental health treatment for Chinese Americans. Journal of Community Psychology, 32(1), 27-43. https://doi.org/10.1002/jcop.10077 
Liddon, L., Kingerlee, R., \& Barry, J. A. (2018). Gender differences in preferences for psychological treatment, coping strategies, and triggers to help-seeking. British Journal of Clinical Psychology, 57(1), 42-58. https://doi.org/10.1111/bjc.12147

Mallen, M. J., \& Vogel, D. L. (2005). Online Counseling: A Need for Discovery. The Counseling Psychologist, 33(6), 910-921. https://doi.org/10.1177/0011000005280182

Newall, N. E., Chipperfield, J. G., Clifton, R. A., Perry, R. P., Swift, A. U., \& Ruthig, J. C. (2009). Causal beliefs, social participation, and loneliness among older adults: A longitudinal study. Journal of Social and Personal Relationships, 26(2-3), 273-290. https://doi.org/10.1177/0265407509106718

Pedersen, S., Vitaro, F., Barker, E. D., \& Borge, A. I. H. (2007). The Timing of MiddleChildhood Peer Rejection and Friendship: Linking Early Behavior to Early-Adolescent Adjustment. Child Development, 78(4), 1037-1051. https://doi.org/10.1111/j.14678624.2007.01051.x

Peplau, L. A. (1982). Perspective on loneliness. Lonelinss: A Sourcebook of Current Theory, Research and Therapy. Retrieved from Google Scholar

Priel, B., \& Shamai, D. (1995). Attachment style and perceived social support: Effects on affect regulation. Personality and Individual Differences, 19(2), 235-241. https://doi.org/10.1016/0191-8869(95)91936-T

Ramaiah, S. (2003). Kecemasan, bagaimana mengatasi penyebabnya. Yayasan Obor Indonesia. Retrieved from Google Scholar

Roberts, R. E., Lewinsohn, P. M., \& Seeley, J. R. (1993). A brief measure of loneliness suitable for use with adolescents. Psychological Reports, 72(3_suppl), 1379-1391. https://doi.org/10.2466/pr0.1993.72.3c.1379

Snell, W. E. (1989). Willingness to Self-Disclose to Female and Male Friends as a Function of Social Anxiety and Gender. Personality and Social Psychology Bulletin, 15(1), 113125. https://doi.org/10.1177/0146167289151011

Solberg, V. S., Ritsma, S., Davis, B. J., Tata, S. P., \& Jolly, A. (1994). Asian-American students' severity of problems and willingness to seek help from university counseling centers: Role of previous counseling experience, gender, and ethnicity. Journal of Counseling Psychology, 41(3), 275-279. https://doi.org/10.1037/0022-0167.41.3.275

Triandis, H. C. (1989). The self and social behavior in differing cultural contexts. Psychological Review, 96(3), 506. http://dx.doi.org/10.1037/0033-295X.96.3.506

Vogel, D. L., Wade, N. G., \& Hackler, A. H. (2007). Perceived public stigma and the willingness to seek counseling: The mediating roles of self-stigma and attitudes toward counseling. Journal of Counseling Psychology, 54(1), 40. https://doi.org/10.1037/00220167.54.1.40

Vogel, D. L., \& Wei, M. (2005). Adult Attachment and Help-Seeking Intent: The Mediating Roles of Psychological Distress and Perceived Social Support. Journal of Counseling Psychology, 52(3), 347-357. https://doi.org/10.1037/0022-0167.52.3.347

Vriends, N., Pfaltz, M. C., Novianti, P., \& Hadiyono, J. (2013). Taijin Kyofusho and Social Anxiety and Their Clinical Relevance in Indonesia and Switzerland. Frontiers in Psychology, 4. https://doi.org/10.3389/fpsyg.2013.00003

Weiner, B. (1985). An attributional theory of achievement motivation and emotion. Psychological Review, 92(4), 548-573. https://doi.org/10.1037/0033-295X.92.4.548 
Intention to Seek Counseling Among Indonesian Students: Examining the Impact of Social Anxiety and Loneliness

Yap, M. B. H., Wright, A., \& Jorm, A. F. (2011). The influence of stigma on young people's help-seeking intentions and beliefs about the helpfulness of various sources of help. Social Psychiatry and Psychiatric Epidemiology, 46(12), 1257-1265. https://doi.org/10.1007/s00127-010-0300-5

Copyright Holder :

(c) Maba, A. P., \& Saputra, A. A. (2019)

First Publication Right :

(c) Islamic Guidance and Counseling Journal

This article is under:

(ㄷ)(1) (2) 